\title{
Fuzzy Quality Control with Reliability and Flexibility
}

\author{
P. Parvathi \\ Head \& Associate Professor, Department of \\ Mathematics, \\ Quaid- E -Millath Government College for \\ Women (Autonomous), \\ Chennai-600002
}

\author{
P. Anitha \\ Assistant Professor, Department of \\ Mathematics, \\ Quaid- E -Millath Government College for \\ Women (Autonomous), \\ Chennai-600002
}

\begin{abstract}
It is commonly observed that the manufacturers have started to give significance to quality management. Promoting the production of the product serves as the ultimate target of the manufacturer. The manufacturers handle various tactics to produce products of high quality and to make it fit for the taste of the customers. To make the rate of production fast, the machines are subjected to continuous wear and tear which results in depreciation. To withstand these circumstances the manufacturers have to maintain high degree of reliability and flexibility. Fuzzy concepts are applied to formulate an Economic Production Quantity (EPQ) model which facilitates the manufacturers to face risks present in the production sector.
\end{abstract}

\section{Keywords}

Production quantity, Fuzzy triangular number, Quality, Reliability, Flexibility

\section{INTRODUCTION}

The Economic Production Quantity (EPQ) is one of the most applicable models in production and inventory control environments. In these days, the manufactures have started to give significance to quality management. The manufacturers handle various tactics to produce products of high quality and to make it fit for the taste of the customers. The manufacturers face internal and external challenges and they require efficient machinery and marketing.

The ultimate target of the manufacturer is promoting the production of the product. Many techniques are available which are helpful to the manufacturers to make their product reach the customers in desirable manner. As the demand varies with time, ordering quantity also varies, we represent these two as triangular fuzzy numbers and have developed this model for the same. Thus in this paper a fuzzy EPQ model is formulated with the integration of various concepts such as depreciation, maintenance and marketing. Flexibility can be increased by installing the new modern flexible production process which, in turn, reduces set - up time and cost in each production cycle. However, acquiring a new and more flexible production process implies considerable capital investments which, results in higher interest and depreciation cost, higher reliability are achievable through substantial investments in factors like production technology, training of personnel, monitoring devices etc.

Presently many marketing techniques are available which assists the manufacturers to make their products reach the consumers in desirable manner.

The generalized form of the Economic Order Quantity by Morteza.et.al., (1) is the oldest and most useful in production and inventory management. The EPQ model has been the basis for building more complex and realistic production models by Ali Yassine.et.al., (2). The production inventory problem has been investigated in recent year, and increasing number of researchers analyze machine breakdown effect in production inventory problem. The effects of machine break down and corrective maintenance on the economic lot sizing were studied by Gede al.et.al., (3). The Mathematical model with random machine break downs and considered preventive maintenance and safety stock were developed by Cheung and Hausman., (4).

This paper is based on W.Ritha and Newatha Martin, (5) in which they developed economic production quantity model which facilitates the manufacturers to face risks present in the production sector, and we have developed the same by taking the demand and order quantity as triangular fuzzy numbers. Using signed distance method we defuzzify the demand and order quantites

\section{PRELIMINARY CONCEPTS}

\subsection{Fuzzy Numbers}

Any fuzzy subset of the real line R, whose membership function $\mu_{\mathrm{A}}$ satisfied the following conditions, is a generalized fuzzy number $\tilde{A}$.

(i) $\mu_{\mathrm{A}}$ is a continuous mapping from $\mathrm{R}$ to the closed interval $[0,1]$, 
(ii) $\mu_{\mathrm{A}}=0,-\infty<x \leq a_{1}$

(iii) $\mu_{\mathrm{A}}=\mathrm{L}(\mathrm{x})$ is strictly increasing on $\left[\mathrm{a}_{1}, \mathrm{a}_{2}\right]$

(iv) $\mu_{\mathrm{A}}=\mathrm{w}_{\mathrm{A}}, a_{2} \leq x \leq a_{3}$

(v) $\mu_{A}=R(x)$ is strictly decreasing on $\left[a_{3}, a_{4}\right]$

(vi) $\mu_{\mathrm{A}}=0, a_{4} \leq x \leq \infty$

Where $0<\mathrm{w}_{\mathrm{A}} \leq 1$ and $\mathrm{a}_{1}, \mathrm{a}_{2}, \mathrm{a}_{3}$ and $\mathrm{a}_{4}$ are real numbers. Also this type of generalized fuzzy number be denoted as $\widetilde{A}=\left(a_{1}, a_{2}, a_{3}, a_{4} ; w_{A}\right)_{L R} ;$ when $\mathrm{w}_{\mathrm{A}}=1$, it can be simplified as $\tilde{A}=\left(a_{1}, a_{2}, a_{3}, a_{4} ; w_{A}\right)_{L R}$.

\section{Triangular fuzzy number}

The fuzzy set $\tilde{A}=\left(a_{1}, a_{2}, a_{3}\right)$ where $\mathrm{a}_{1}<\mathrm{a}_{2}<\mathrm{a}_{3}$ and defined

on $\mathrm{R}$, is called the triangular fuzzy number, if the membership function of $\tilde{A}$ is given by

$\mu_{A}=\left\{\begin{array}{l}\frac{x-a_{1}}{a_{2}-a_{1}}, a_{1} \leq x \leq a_{2} \\ \frac{a_{3}-x}{a_{3}-a_{2}}, a_{2} \leq x \leq a_{3} \\ 0, \text { otherwise }\end{array}\right.$

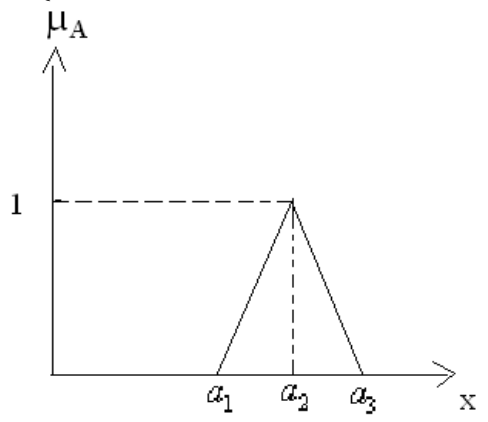

Fig. 1

\section{THE FUNCTION PRINCIPLE}

The function principle was introduced by Chen [6] to treat fuzzy arithmetical operations. This principle is used for addition, subtraction, multiplication and division of fuzzy numbers.

Suppose $\tilde{A}=\left(a_{1}, a_{2}, a_{3}\right)$ and $\tilde{B}=\left(b_{1}, b_{2}, b_{3}\right)$ are two triangular fuzzy numbers. Then

(i) The addition of $\tilde{A}$ and $\tilde{B}$ is

$$
\widetilde{A}+\widetilde{B}=\left(a_{1}+b_{1}, a_{2}+b_{2}, a_{3}+b_{3}\right)
$$

where $a_{1}, a_{2}, a_{3}, b_{1}, b_{2}, b_{3}$ are any real numbers.

(ii) The multiplication of $\tilde{A}$ and $\tilde{B}$ is $\widetilde{A} \times \widetilde{B}=\left(c_{1}, c_{2}, c_{3}\right)$

where

$T=\left(a_{1} b_{1}, a_{1} b_{3}, a_{3} b_{1}, a_{3} b_{3}\right), c_{1}=\min T, c_{2}=a_{2} b_{2}, c_{3}=\max T$ if $a_{1}, a_{2}, a_{3}, b_{1}, b_{2}, b_{3}$ are all non zero positive real numbers, then $\widetilde{A} \times \widetilde{B}=\left(a_{1} b_{1}, a_{2} b_{2}, a_{3} b_{3}\right)$.

(iii) $-\widetilde{B}=\left(-b_{3},-b_{2},-b_{1}\right)$ then the subtraction of $\tilde{B}$ from $\tilde{A}$ is $\tilde{A}-\widetilde{B}=\left(a_{1}-b_{3}, a_{2}-b_{2}, a_{3}-b_{1}\right)$ where $\mathrm{a}_{1}, \mathrm{a}_{2}, \mathrm{a}_{3}, \mathrm{~b}_{1}, \mathrm{~b}_{2}, \mathrm{~b}_{3}$ are any real numbers.

(iv) $\frac{1}{\widetilde{B}}=\widetilde{B}^{-1}=\left(\frac{1}{b_{3}}, \frac{1}{b_{2}}, \frac{1}{b_{1}}\right)$ where $\mathrm{b}_{1}, \mathrm{~b}_{2}, \mathrm{~b}_{3}$ are all non zero positive real numbers, then the division of $\tilde{A}$ and $\tilde{B}$ is $\frac{\widetilde{A}}{\widetilde{B}}=\left(\frac{a_{1}}{b_{3}}, \frac{a_{2}}{b_{2}}, \frac{a_{3}}{b_{1}}\right)$

(v) For any real number K,

$$
\begin{aligned}
& K \tilde{A}=\left(K a_{1}, K a_{2}, K a_{3}\right) \text { if } K>0 \\
& K \tilde{A}=\left(K a_{3}, K a_{2}, K a_{1}\right) \text { if } K<0
\end{aligned}
$$

\section{Signed Distance Method}

Defuzzification of $\tilde{A}$ can be found by signed distance method. If $A$ is a triangular fuzzy number and is fully determined by $\left(\mathrm{a}_{1}, \mathrm{a}_{2}, \mathrm{a}_{3}\right)$, the signed distance from $\tilde{A}$ to 0 is defined as

$$
\begin{gathered}
d(\tilde{A}, \tilde{0})=\int_{0}^{1} d\left(\left[A_{L}(\alpha), A_{R}(\alpha)\right], \tilde{0}\right) d \alpha \\
=\frac{\left(a_{1}+4 a_{2}+a_{3}\right)}{4}
\end{gathered}
$$

\section{PROBLEM STATEMENT}

Consider a manufacturer who produces a single product by employing highly advanced machinery .As the production process is carried on in full swing to satisfy the customers' demands the machines are subjected to continuous working which starts to depreciate over a period of time. To avoid the machine breakdown, the manufacturers maintain the quality of the machines by periodical inspection, repairing the worn out parts of the machine with the assistance of skilled laboures, tooling, 
machine cleaning and so on. Also to promote the status of the products the manufacturers are in need of marketing strategies. Therefore the expenditure of the manufacturer not only includes set up cost, production costs and holding costs but also it comprises of expenditure spent for maintaining high degree of quality, reliability and flexibility.

\section{Notations and Assumptions}

The following notations and assumptions have been used to develop the fuzzy mathematical model.

\section{Notations}

D Demand per unit of time

$\mathrm{P} \quad$ Production per unit of time

$\beta \quad$ The fraction of time the production process spends $\left(\frac{D}{P}\right)$

1- $\beta$ The fraction of time the production process spends actually idling

Q Economic production Quantity

A Fixed ordering cost per production run

$\mathrm{h} \quad$ Holding cost per unit per unit of time.

c unit production cost

$\mathrm{p}_{\mathrm{i}} \quad$ proportion of cost of machine

$\mathrm{m}_{\mathrm{i}}(\mathrm{i}=1, \ldots . . \mathrm{n})$ depreciated

$\mathrm{C}_{\mathrm{i}} \quad$ cost of the machine $\mathrm{m}_{\mathrm{i}}(\mathrm{i}=1, \ldots . \mathrm{n})$

$f_{i} \quad$ maintenance cost of machine $m_{i}(i=1, \ldots . n)$

$\mathrm{M}_{\mathrm{i}} \quad$ volume of investments in marketing method $\mathrm{i}=1, \ldots \mathrm{k}$ per unit time

$\mathrm{T} \quad$ cycle length

$\tilde{D}=\left(D_{1}, D_{2}, D_{3}\right)$ Fuzzy Demand per unit of time.

$\tilde{Q}=\left(\mathrm{Q}_{1}, \mathrm{Q}_{2}, \mathrm{Q}_{3}\right) \quad$ Fuzzy Production Quantity per cycle

\section{Assumptions}

1. Production rate is constant.

2. Replenishment is instantaneous.

3. No excess stock is carried and no shortage is allowed.

4. The fuzzy production quantity is produced in batches.

5. Depreciation is the function of use.

The EPQ cost per unit of time

$$
C(\tilde{Q})=A \frac{\tilde{D}}{\tilde{Q}}+\frac{h \tilde{Q}(1-\beta)}{2}
$$

The Production cost per cycle

$$
C_{p}(\tilde{Q})=c \tilde{Q}
$$

\section{The Depreciation cost per cycle}

Suppose that the manufacturers owns machine $\mathrm{m}_{\mathrm{i}}(\mathrm{i}=1, \ldots . \mathrm{n})$ to execute sequentially the various tasks involved in the the production process. It is quite naturals for the machine to get degraded due to continuous wear and tear, so the value of the machines gets depreciated .The proportion $\left(p_{i}\right)$ of costs of machine $m_{i}(i=1, \ldots . n)$ depreciated is determined by various methods and it varies from one machine to another. Therefore the depreciated cost per cycle is as follows.

$$
C_{\tilde{D}}(\tilde{Q})=\sum_{i=1}^{n} p_{i} C_{i}=L \text { (say) }
$$

\section{The Maintenance cost per cycle}

To maintain the degree of reliability and to prevent machine break down the machine have to be properly taken care. Since each machine serves different purposes the pattern of its maintenance also differs. Therefore the maintenance per cycle is as follows.

$$
C_{M}(\tilde{Q})=\sum_{i=1}^{n} f_{i}=F \text { (say) }
$$

\section{The Marketing cost per cycle}

To propagate the product in the marker rapidly the manufacturers may prefer one or more marketing strategies, (i.e) for example the manufacturer may advertise his products via two modes viz. Newspaper and Television for which separate cost are incurred. Therefore the marketing cost per cycle is as follows

$C_{A}(\tilde{Q})=\sum_{i=1}^{k} M_{i}=S$ (say)

\section{Total cost per unit of time}

$$
\begin{gathered}
\Psi(\tilde{Q})=C(\tilde{Q})+\frac{C_{p}(\tilde{Q})+C_{\tilde{D}}(\tilde{Q})+C_{M}(\tilde{Q})+C_{A}(\tilde{Q})}{T} \\
\text { where } T=\frac{\tilde{Q}}{\tilde{D}} \\
A \frac{\tilde{D}}{\tilde{Q}}+h \frac{\tilde{Q}(1-\beta)}{2}+c \tilde{D}+\frac{\tilde{D}}{\tilde{Q}}(L+F+S)
\end{gathered}
$$




$$
\frac{\partial \psi(\tilde{Q})}{\partial \widetilde{Q}}=\frac{\partial}{\partial \tilde{Q}}\left(\begin{array}{c}
A \frac{\tilde{D}}{\tilde{Q}}+h \frac{\tilde{Q}(1-\beta)}{2} \\
+c \tilde{D}+\frac{\tilde{D}}{\tilde{Q}}(L+F+S)
\end{array}\right)
$$$$
=A\left(\frac{-\tilde{D}}{\widetilde{Q}^{2}}\right)+h \frac{(1-\beta)}{2}-\frac{\tilde{D}}{\widetilde{Q}^{2}}(L+F+S)
$$$$
\frac{\partial^{2} \psi(\tilde{Q})}{\partial \widetilde{Q}^{2}}=+\frac{2 \tilde{D}}{\widetilde{Q}^{3}}(A+L+F+S)>0
$$

Therefore $\Psi(\tilde{Q})$ is concave with respect to $\tilde{Q}$

By equating $\frac{\partial \psi(\tilde{Q})}{\partial \widetilde{Q}}$ to zero we can find the optimal value of $\tilde{Q}$

$$
\begin{gathered}
\frac{\partial \psi(\tilde{Q})}{\partial \tilde{Q}}=0 \Rightarrow \frac{-\tilde{D}}{\tilde{Q}^{2}}(A+L+F+S) \\
=\frac{h(1-\beta)}{2} \\
\tilde{Q}=\sqrt{\frac{2 \tilde{D}[A+L+F+S]}{h(1-\beta)}}
\end{gathered}
$$

\section{NUMERICAL EXAMPLE}

In this section, a numerical example is carried out to illustrate the model

\section{Example - 1}

In an inventory cum production systemconsider the following data.

$\mathrm{n}=3$,

$\mathrm{k}=2$,

$\mathrm{C}_{1}=$ Rs.10,000, $\mathrm{C}_{2}=\mathrm{Rs} .20,000, \mathrm{C}_{3}=\mathrm{Rs} .30,000, \mathrm{p}_{1}=$ $1 \%, \mathrm{p}_{2}=2 \%, \mathrm{p}_{3}=1 \%$

$\mathrm{f}_{1}=$ Rs.500, $\mathrm{f}_{2}=$ Rs. $1000, \mathrm{f}_{3}=$ Rs. 1500 ,

$\mathrm{M}_{1}=$ Rs.200, $\quad \mathrm{M}_{2}=$ Rs.2000,

A= Rs. 200
$\widetilde{D}=(500,1000,1500)$,

$\mathrm{h}=$ Rs. 4 ,

$\mathrm{P}=1000$ per unit time.

Using these data we find

$L=800$

$F=3000$

$\mathrm{S}=2200$

$\beta=(0.2,0.4,0.6)$

$\tilde{Q}=(880,493,2156)$

Defuzzify $\tilde{Q}$ used signed distance method

$$
Q=1252 \text { per unit time }
$$

\section{Example - 2}

In an inventory cum production systemconsider the following data

$\mathrm{n}=3$,

$\mathrm{k}=3$,

$\mathrm{C}_{1}=$ Rs.10,000, $\mathrm{C}_{2}=$ Rs. $15,000, \mathrm{C}_{3}=$ Rs. 20,000,

$\mathrm{p}_{1}=0.5 \%, \mathrm{p}_{2}=0.3 \%, \mathrm{p}_{3}=1 \%$

$\mathrm{f}_{1}=$ Rs. $1000, \mathrm{f}_{2}=$ Rs. $1500, \mathrm{f}_{3}=$ Rs. 2000 ,

$\mathrm{M}_{1}=$ Rs. $500, \mathrm{M}_{2}=$ Rs. $1000, \mathrm{M}_{3}=$ Rs. 2000

$\mathrm{A}=$ Rs. 300

a $\widetilde{D}=(1000,1500,1800)$

$\mathrm{h}=$ Rs. .5 ,

$\mathrm{P}=2000$ per unit time.

Using these data we find

$L=295$

$F=4500$

$\mathrm{S}=3500$

$\tilde{Q}=(2622,4542,8292)$

Defuzzify $\tilde{Q}$ used signed distance method

$Q=7271$ per unit time 


\section{CONCLUSION}

This model is highly beneficial to the manufacturer as the EPQ model is focused on quality, reliability and flexibility. This model can put into practice as it enables the manufacturers to tackle both the internal and external challenges, there by increasing the promotion of the product in the market leading to mass profit.

Thus a fuzzy economic production quantity model is formulated with the integration of various concepts such as depreciation, maintenance and marketing.

\section{REFERENCES}

[1] Morteza Rasti Barzoki, Morteza Jahanbazi, Mehdi Bijari. (2011). Effects of imperfect products on lot sizing with work in process inventory., Applied Mathematicas and Computation 217 (2011) 83288336.
[2] Ali Yassine, Bacel Maddah, Moueen Salameh. (2012). Disaggregation and consolidation of imperfect quality shipments in an extended EPQ model., Int. J. Prodection Economics 135,345-352b.

[3] Gede Agus Widyadana, Hui Ming Wee. (2011). Optimal deteriorating items production inventory models with random machine breakdown and stochastic repair time., Applied Mathematical Modeling 35, 3495-3508.

[4] Cheung, L.L., \& Hausman, W.H.(1997). Joint determination of preventive maintenance and safety stocks in unreliable production environment, Naval Res. Log.44, 257-272.

[5] W.Ritha and Nivetha Martin, (2012). An Inventory Model with Quality, Reliability and Flexibility., International Conference and Mathematical Modeling and Applied Soft Computing, Volume-I. 